\title{
RANCANG BANGUN ANTENA LOG PERIODIC DIPOLE ARRAY UNTUK PENGUKURAN RADIASI ELEKTROMAGNETIK BTS
}

\author{
Haryo Dwi Prananto*, Priyo Wibowo \\ Pusat Penelitian Sistem Mutu dan Teknologi Pengujian, Lembaga Ilmu Pengetahuan Indonesia \\ "Corresponding author, e-mail: haryo.dwi.prananto@lipi.go.id
}

\begin{abstract}
Abstrak - Telah dilakukan rancang bangun antena mikrostrip log periodic dipole antenna (LPDA) yang akan digunakan sebagai alat ukur radiasi medan elektromagnetik pada base trransceiver station (BTS). Sebelum dijadikan alat ukur radiasi medan elektromagnetik BTS, karakteristik antena dilihat terlebih dahulu dari sisi return loss, dan pola radiasi yang dihasilkan. Desain antena LPDA menggunakan spesifikasi khusus dengan parameter $\tau=0.88$ dan $\sigma=0.12$. Pembuatan antena secara mikrostrip dengan bahan dielektrik berupa FR4 sebagai substrat dan elemen antena berupa tembaga. Pengukuran return loss menggunakan network analyzer dan pola radiasi diukur di semi anechoic chamber $3 \mathrm{~m}$ di frekuensi operasi kerja BTS Indonesia (frekuensi 850, 900, 1800, 2100, dan $2300 \mathrm{MHz}$ ). Hasilnya pada setiap frekuensi nilai return loss yang didapat baik karena bernilai dibawah -10 dB. Sedangkan pola radiasinya yang dihasilkan berbentuk direksional pada setiap frekuensi. Pada frekuensi 850 dan $900 \mathrm{MHz}$ back lobes yang ada pada pola radiasi yang dihasilkan cukup besar nilainya mendekati nilai main lobes. Sedangkan pada frekuensi $2100 \mathrm{MHz}$, side lobes yang ada mendekati nilai main lobes. Hal ini merupakan hasil yang kurang maksimal, sehingga antena LPDA yang dibuat cukup baik digunakan di frekuensi $1800 \mathrm{MHz}$ dan $2300 \mathrm{MHz}$.
\end{abstract}

Kata Kunci : antena mikrostrip LPDA, return loss, dan pola radiasi

\begin{abstract}
The Microstrip Antenna Log Periodic Dipole Array has been design and create as measuring device for electromagnetic field on base transceiver station (BTS). Before it use for measuring device, characterictics of antenna must be known from return loss and radiation pattern. The design of antenna has special specification which it use $\tau=0.88$ and $\sigma=0.12$ as parameter. Material of antenna from FR 4 dielectric material as substrate and element from chopper. Measuring return loss with networ analyzer and radiation pattern in $3 \mathrm{~m}$ semi anechoic chamber at frequencies 850, 900, 1800, 2100, and $2300 \mathrm{MHz}$. The result of return loss from each frequencies is good because the values is below than $-10 \mathrm{~dB}$. Whereas the radiation pattern is directional type to each frequency. Frequency antena at 850 and $900 \mathrm{MHz}$, back lobes that exist in the radiation pattern generated sizeable value approaching the value of the main lobes. While in the $2100 \mathrm{MHz}$ frequency, side lobes that is closer to the value of the main lobes. This is less than the maximum results, so that the antenna LPDA made pretty good use in the frequency of $1800 \mathrm{MHz}$ and 2300 $\mathrm{MHz}$.
\end{abstract}

Keywords : Microstrip antenna LPDA, return loss, and radiation pattern

Copyright $\odot 2017$ JNTE. All rights reserved

\section{PENDAHULUAN}

Base transceiver station (BTS) memegang peranan penting dalam sistem komunikasi. BTS berperan penting dalam memfasilitasi komunikasi nirkabel antara pengguna jaringan komunikasi (mobile phone) dengan operator telekomunikasi seluler [1].

BTS menerima sinyal dari pengguna mobile phone (dalam hal ini sebagai pengirim sinyal) untuk diproses dan dilanjutkan ke jaringan dan ke telepon lainnya sebagai penerima. Sebelum dikirim ke penerima sinyal tersebut diperkuat sampai level yang dipersyaratkan. Karena sifatnya sebagai sarana dalam sistem transmisi komunikasi ini, maka otomatis BTS akan menjadi sumber yang akan memancarkan radiasi medan elektromagnetik, yang akan memberi pengaruh pada lingkungan sekitarnya [2].

Untuk mengetahui seberapa besar medan elektromagnetik yang dipancarkan oleh BTS, diperlukan antena sebagai pengukur radiasi medan tersebut. Antena yang cukup baik digunakan untuk keperluan tersebut adalah jenis antena log periodic dipole array (LPDA). Antena LPDA merupakan antenna jenis direksional dan sangat baik untuk semua aplikasi yang membutuhkan rentang frekuensi yang lebar 
disertai dengan penguatan yang wajar [3]. Selain itu jika jika antenna LPDA dibuat versi mikrostripnya, kelebihannya bertambah yaitu ukuran yang kecil, ringan, mudah dibuat, pola radiasi yang terarah [4].

Berbagai penelitian-penelitian telah dilakukan untuk pengembangan antenna mikrostrip LPDA. Seperti pada penelitian Karim dkk [5], antenna LPDA cetak yang dibuat memiliki rentang frekuensi yang luas yaitu pada rentang UHF $(0,5 \mathrm{GHz}-3 \mathrm{GHz})$ dengan nilai return loss dan pola radiasi dari penelitian tersebut pun cukup baik. Nilai return loss yang didapat penelitian tersebut adalah di bawah -10 $\mathrm{dB}$ dari rentang $0,5 \mathrm{GHz}-4 \mathrm{GHz}$. Sedangkan Pola radiasinya bernilai tinggi dan directional pada sudut $0^{\circ}-120^{\circ}$ dan $240^{\circ}-360^{\circ}$. Hasil yang diperoleh dari penelitian tersebut didapat dengan rancangan $\tau$ sebesar 0.85 . Penelitian lainnya dilakukan oleh Casula dkk [6] dengan rentang frekuensi dan perancangan antena LPDA cetak yang berbeda. Rentang frekuensi yang digunakan adalah $2,4-3 \mathrm{GHz}$ dan $5,2-5,8 \mathrm{GHz}$ dengan $\tau=0.95$.

Penelitian-penelitian diatas menggunakan $\tau$ 0.95 dan 0.85. Pada penelitian ini dibuatlah antenna mikostrip LPDA dengan pemilihan $\tau$ sebesar 0.8 dan $\sigma$ sebesar 0.12 dengan rentang frekuensi kerja BTS yaitu $800 \mathrm{MHz}-2400$ MHz.

Pemilihan $\tau$ dan $\sigma$ didasarkan pada pertimbangan akan dimensi antenna dan gain yang akan digunakan. Dengan nilai tersebut, dimensi antena akan akan menjadi lebih berkurang namun dengan gain yang wajar yaitu berkisar $6.5 \mathrm{~dB}$, sehingga cocok menjadi pengukur radiasi BTS yang mudah dibawa dan tidak memerlukan penguat daya lagi.

\section{TINJAUAN PUSTAKA}

\subsection{Antena LPDA}

Antena LPDA merupakan susunan antenna dipol yang dipasang berurutan dan sejajar [7]. Antena tersebut dapat dibuat dengan beberapa ketentuan berdasarkan rentang frekuensi yang diinginkan. Dimana rentang frekuensi tersebut mempengaruhi jumlah elemen antenna yang ingin dibuat yaitu sesuai dengan persamaan berikut [8]:

$N=1+\frac{\ln \left(B \cdot B_{A R}\right)}{\ln \left(\frac{1}{\tau}\right)}$
$\mathrm{B}$ merupakan bandwidth sedangkan $\mathrm{B}_{\mathrm{AR}}$ merupakan bandwidth pada daerah aktif antena. $\mathrm{B}$ dan $\mathrm{B}_{\mathrm{AR}}$ didapatkan dari [9]:

$\mathrm{B}=\frac{f_{\text {max }}}{f_{\text {min }}}$

$B_{A R}=1,1+7,7(1-\tau)^{2} \cot \alpha$

Definisi $f_{\max }$ adalah batas atas frekuensi maksimum dan $f_{\min }$ adalah batas bawah frekuensi minimum antena. Sedangkan $\cot \alpha$ merupakan sudut antara feedline dengan ujung panjang elemen antena. Simbol $\tau$ merupakan konstanta desain antena LPDA yang dapat ditentukan pada Gambar 1 sesuai dengan gain yang diinginkan.

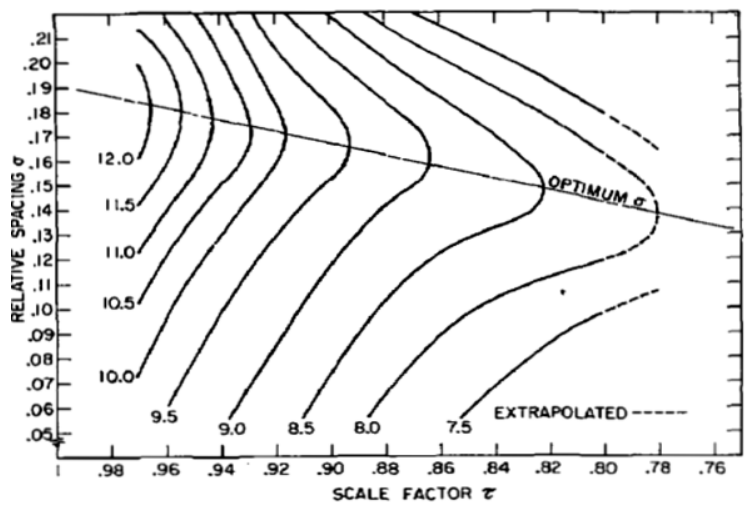

Gambar 1. Kontur directivity antena LPDA yang ditunjukkan fungsi $\sigma$ dengan fungsi $\tau$ [8].

Kemudian mencari panjang elemen antena pada mikrostrip dengan menggunakan persamaan [5]:

$l=0.5 \times v / f$

Dimana $v$ merupakan cepat rambat cahaya pada dielektrik suatu media yang dipakai dalam pembuatan antenna mikrostrip. Sedangkan $f$ adalah frekuensi yang digunakan.

Kemudian mencari jarak antara elemen satu dengan elemen $\left(S_{n}\right)$ lainnya menggunakan persamaan [6]:

$S_{n}=\sigma 4 l_{n}$

Panjang dan jarak antar elemen selanjutnya dapat dicari melalui $\tau$ yang dipilih sebelumnya menggunakan persamaan berikut [7]: 


$$
\tau=\frac{l_{n}}{l_{n+1}}=\frac{s_{n}}{s_{n+1}}=\frac{w_{n}}{w_{n+1}}
$$

\subsection{Return Loss}

Return loss merupakan nilai perbandingan antara besarnya amplitudo dari daya yang dipantulkan dengan amplitudo dari gelombang yang ditransmisikan. Parameter ini umumnya dinyatakan sebagai perbandingan dalam satuan desibel (dB) dalam tanda negatif. Return Loss dapat didefinisikan seperti pada persamaan 7 [10][11]:

$R_{L}=-20 \log _{10}|\Gamma|$

Dimana $\Gamma$ merupakan koefisien refleksi $\left(\mathrm{S}_{11}\right)$.

\subsection{Pola Radiasi}

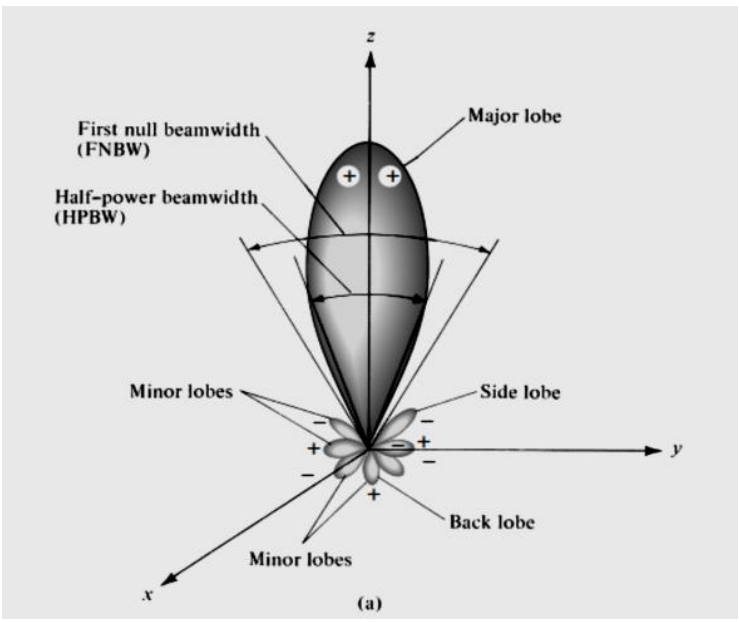

Gambar 2. Subklasifikasi lobes pada pola radiasi [7]

Pola radiasi merupakan penggambaran distribusi energy yang dipancarkan antenna di ruang bebas. Pola radiasi memiliki berbagai bagian yang dinamakan lobes. Lobes dapat disubklasifikasikan menjadi major lobe, minor lobe, side lobe, dan back lobe seperti yang diperlihatkan pada gambar 2. Lobes yang ada di pola radiasi dapat menandakan sifat pancar suatu antenna. Sifat pancar tersebut dapat berupa direksional (arah pancar ke hanya ke satu arah), omnidireksional (arah pancar ke berbagai arah dengan energy pada satu bidang sama besar), ataupun isotropis (arah pancaran ke segala arah dengan energi sama besar di pada seluruh bidang) [7].

\section{METODOLOGI}

\subsection{Desain Antena Mikrostrip LPDA}

Antena dirancang sesuai dengan rentang frekuensi operasi BTS yaitu di rentang $800-$ $2400 \mathrm{MHz}, \tau=0.8$ dan $\sigma=0.12$. Parameterparameter tersebut digunakan dalam pembuatan desain antenna LPDA dengan menggubakan persamaan-persamaan yang dijelaskan bagian sebelumnya.

Berdasarkan desain yang dibuat didapatkan antena dengan spesifikasi yang terlihat pada tabel berikut ini:

Tabel 1. Spesifikasi desain antenna mikrostrip LPDA yang dibuat

\begin{tabular}{|c|c|c|c|}
\hline Dipole & $\ln$ & Sn & wn \\
\hline 1 & 15.2 & & 3.30 \\
\hline 2 & 19.0 & 9.10 & 4.13 \\
\hline 3 & 23.7 & 11.37 & 5.17 \\
\hline 4 & 29.6 & 14.22 & 6.46 \\
\hline 5 & 37.0 & 17.77 & 8.07 \\
\hline 6 & 46.3 & 22.22 & 10.09 \\
\hline 7 & 57.9 & 27.77 & 12.62 \\
\hline 8 & 72.3 & 34.71 & 15.77 \\
\hline 9 & 90.4 & 43.39 & 19.72 \\
\hline
\end{tabular}

\subsection{Pembuatan Antena mikrostrip LPDA}

Gambar 3 merupakan antena LPDA cetak yang telah dibuat dengan dimensi $19.8 \mathrm{~cm}$ x 20.5 $\mathrm{cm}$. Pembuatan antena menggunakan bahan FR4 sebagai substrat dan tembaga sebagai elemen antenna. Konektor yang digunakan adalah female SMA connector dengan lebar feedline $3.137 \mathrm{~mm}$.

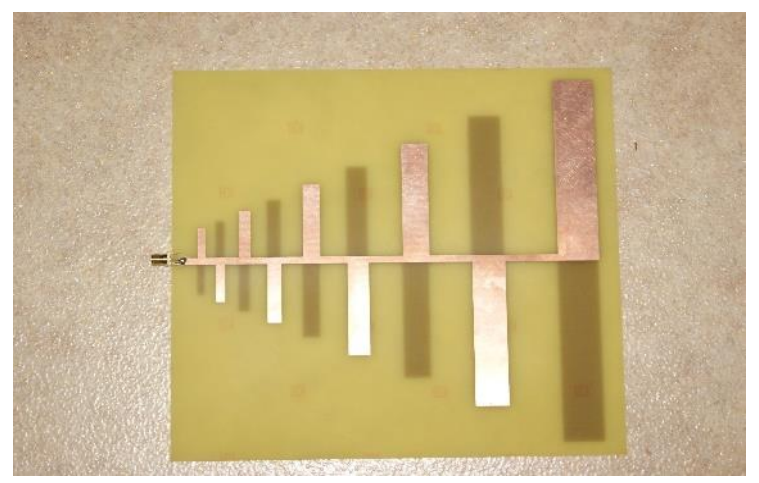

Gambar 3. Foto antenna mikrostrip yang telah dibuat 


\subsection{Pengukuran Return Loss}

Gambar 4 menunjukkan pengukuran return loss pada antena mikrostrip LPDA dengan menggunakan network analyzer. Nilai return loss diambil pada rentang frekuensi kerja BTS di frekuensi GSM dan CDMA yang aktif beroperasi di Indonesia yaitu frekuensi 850, 900, 1800, 2100, dan 2300 MHz. [12]

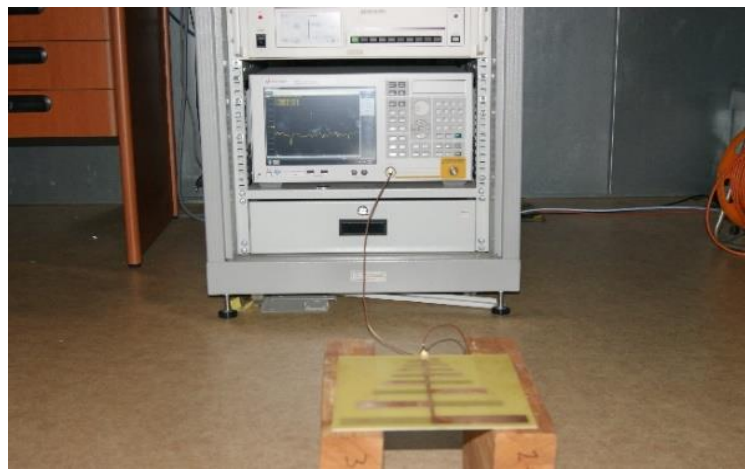

Gambar 4. Pengukuran return loss antena mikrostrip LPDA menggunakan network analyzer

\subsection{Pola Radiasi}

Gambar 5 dan 6 menunjukkan pengambilan data pola radiasi far-field pada semi anechoic chamber $3 \mathrm{~m}$. Pada gambar 5, pengambilan pola radiasi di frekuensi dibawah $1 \mathrm{GHz}$ (850 dan 900 $\mathrm{MHz}$ ) dimana diantara antena yang diukur dan diukur dipasang ferit sebagai penyerap medan elektromagnetik. Sedangkan pada gambar 6, pengambilan pola radiasi pada frekuensi diatas 1 GHz (1800, 2100, dan $2300 \mathrm{MHz})$ yang penyerap gelombang elektromagnetik berupa pyramid cone.

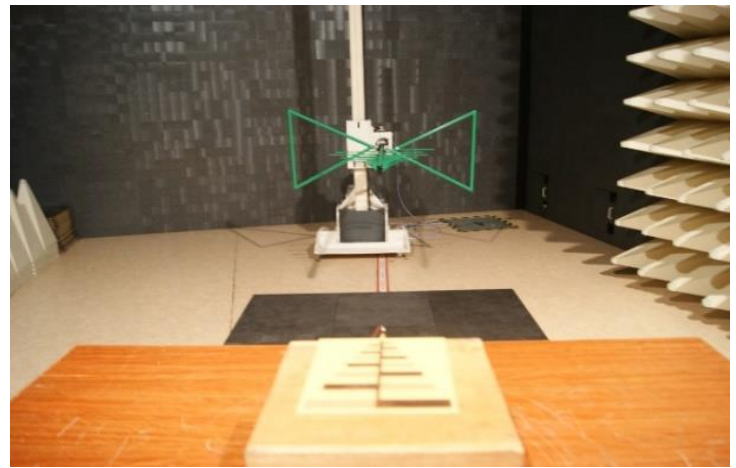

Gambar 5. Pengukuran pola radiasi antena mikrostrip LPDA di semi anechoic chamber $3 \mathrm{~m}$ di frekuensi dibawah $1 \mathrm{GHz}$.
Antena mikrostrip LPDA Cetak diletakkan pada meja yang dapat berputar $360^{\circ}$ terhadap antena pengukur. Jarak antena pengukur dengan antena LPDA Cetak yang disebut antenna under test (AUT) adalah $3 \mathrm{~m}$ dimana kedua antenna berada di posisi horizontal. Antena pengukur merupakan antena jenis bilog, gabungan antara antena jenis LPDA dan bow-tie. Antena mikrostrip LPDA diberikan sinyal sebesar 80 $\mathrm{dB} \mu \mathrm{V}$ oleh signal generator. Pola radiasi diambil pada frekuensi yang sama saat pengambilan data nilai return loss.

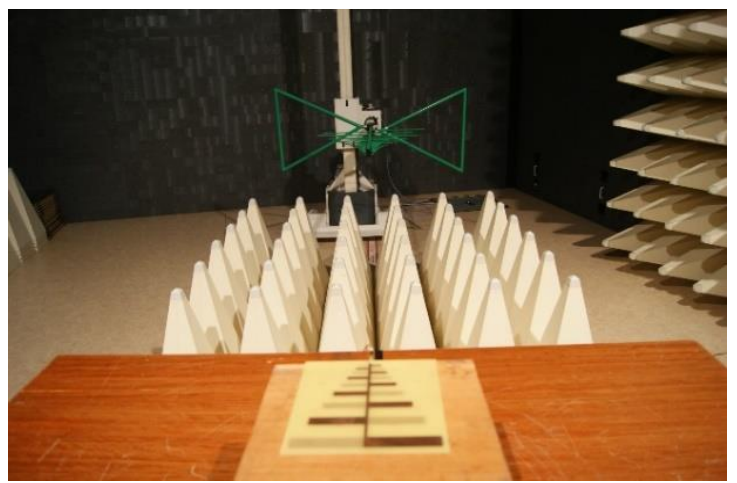

Gambar 6. Pengukuran pola radiasi antena mikrostrip LPDA di semi anechoic chamber $3 \mathrm{~m}$ di frekuensi diatas 1 $\mathrm{GHz}$

\section{HASIL DAN PEMBAHASAN}

\subsection{Return Loss}

Data return loss yang didapat pada frekuensi kerja BTS ditampilkan pada tabel berikut:

Tabel 2. Data return loss di setiap frekuensi

\begin{tabular}{|c|c|}
\hline Frekuensi (MHz) & Return Loss (dB) \\
\hline 850 & -11.576 \\
\hline 900 & -11.852 \\
\hline 1800 & -14.796 \\
\hline 2100 & -15.049 \\
\hline 2300 & -18.424 \\
\hline
\end{tabular}

Nilai return loss pada semua frekuensi yang terdapat pada tabel 2 tersebut termasuk baik karena nilainya dibawah $-10 \mathrm{~dB}$ [13]. Nilai tersebut menunjukkan bahwa gelombang yang direfleksikan antena sangat kecil bila dibandingkan dengan gelombang yang salurkan. Hal itu menunjukkan efisiensi antena sebagai antena pemancar maupun penerima. 


\subsection{Pola Radiasi}

Gambar 7, 8, 9, 10, dan 11 menunjukkan pola radiasi yang dihasilkan antena mikrostrip LPDA pada frekuensi 850, 900, 1800, 2100, dan $2300 \mathrm{MHz}$. Pola radiasi yang dihasilkan pada setiap frekuensi merupakan pola radiasi direksional. Hal tersebut dibuktikan pada setiap pola radiasi hanya memiliki sebuah main lobe . Pada frekuensi 850, 900, dan $1800 \mathrm{MHz}$, main lobe mengarah ke sudut $0^{\circ}$, sedangkan pola radiasi pada frekuensi 2100 dan 2300 mengarah ke sudut $-10^{\circ}$.

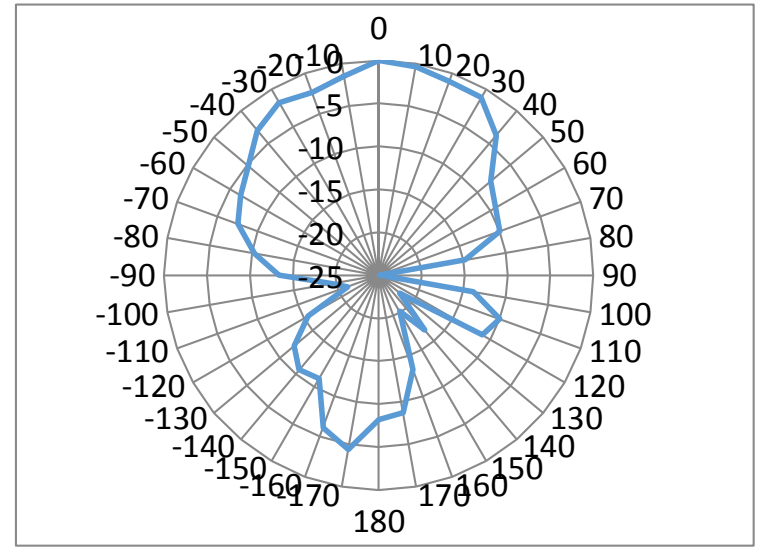

Gambar 7. Pola radiasi antenna mikrostrip LPDA pada frekuensi $850 \mathrm{MHz}$.

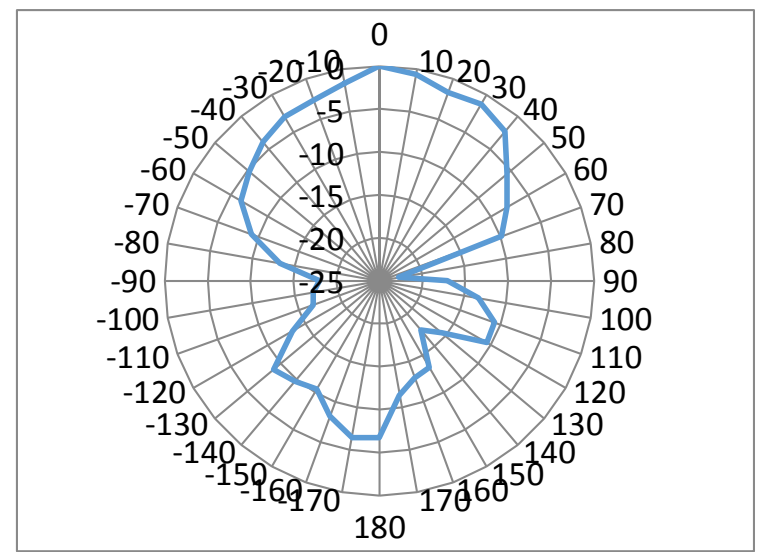

Gambar 8. Pola radiasi antenna mikrostrip LPDA pada frekuensi $900 \mathrm{MHz}$.

Pada frekuensi 850, 900, dan $2300 \mathrm{MHz}$ pola radiasi yang dihasilkan kurang maksimal bila dihubungkan dengan pola radiasi antenna LPDA yang berjenis direksional. Pada frekuensi 850 dan $900 \mathrm{MHz}$ back lobe yang dihasilkan cukup besar dibanding dengan main lobe. Sedangkan di frekuensi $2100 \mathrm{MHz}$ side lobe yang dihasilkan cukup besar mendekati main lobe.

Hal tersebut kurang baik karena dapat menyebabkan pembacaan medan elektromagnetik tidak terfokus ke satu arah melainkan dan akan mengganggu pengukuran. Selain itu juga akan berpeluang terjadinya kesalahan target saat pengukuran.

Penyebab dari hasil tersebut mungkin dikarenakan posisi connector SMA yang ada di ujung dekat elemen antena frekuensi tinggi (Nilai $L_{n}$ yang kecil).

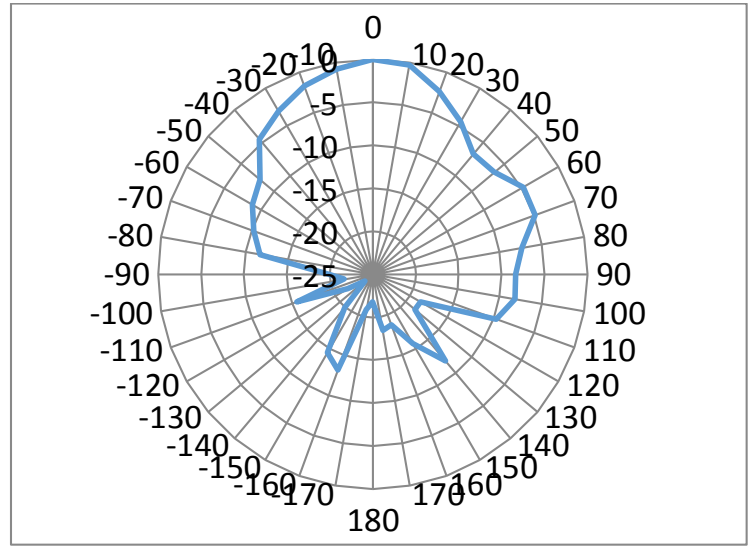

Gambar 9. Pola radiasi antenna mikrostrip LPDA pada frekuensi $1800 \mathrm{MHz}$.

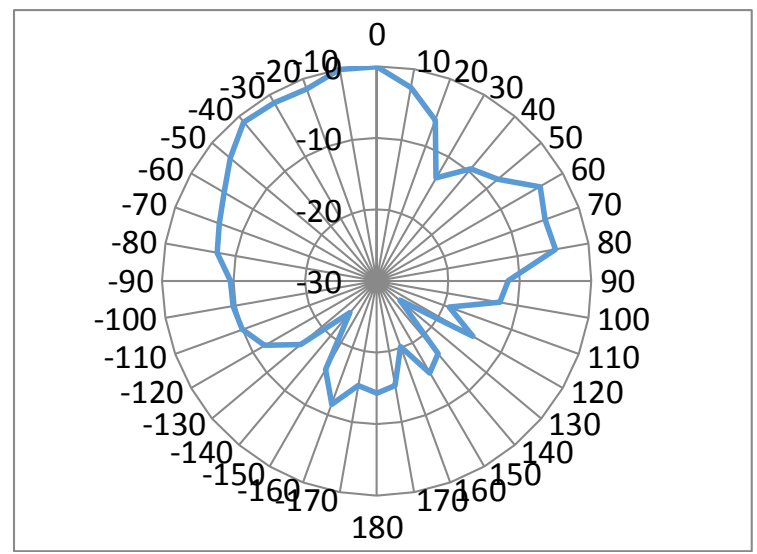

Gambar 10. Pola radiasi antenna mikrostrip LPDA pada frekuensi $2100 \mathrm{MHz}$.

Connector SMA tersebut membuat elemen antena di frekuensi rendah $\left(\mathrm{L}_{\mathrm{n}}\right.$ bernilai besar) tetap memancarkan medan elektromagnetnya saat di posisi $180^{\circ}$ dengan nilai yang cukup besar.

Sementara untuk frekuensi 1800 dan 2300 $\mathrm{MHz}$, pola radiasi yang dihasilkan cukup baik karena main lobe yang dimiliki hanya ada 1 dan 
back lobes serta side lobes nilainya tidak begitu besar dibandingkan main lobes yang dihasilkan.

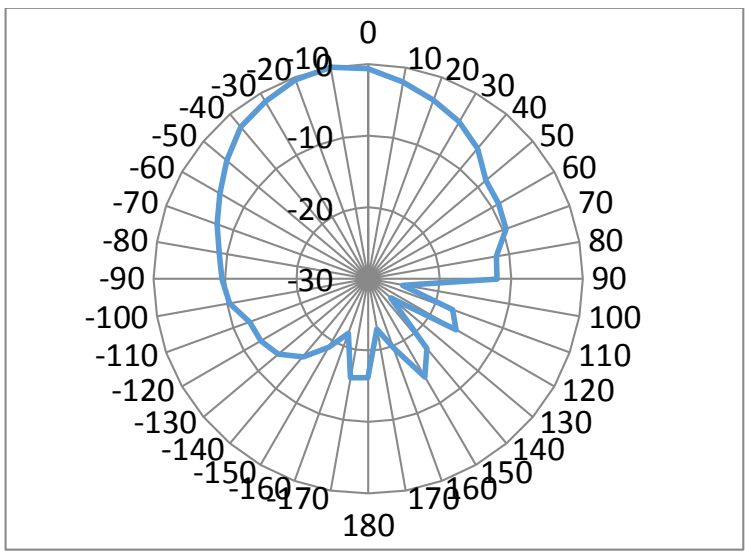

Gambar 11. Pola radiasi antenna mikrostrip LPDA pada frekuensi $2300 \mathrm{MHz}$.

\section{KESIMPULAN}

Antena mikrostrip LPDA telah berhasil dibuat dengan rancangan rentang frekuensi 800 - $2400 \mathrm{MHz}$ dengan parameter $\tau$ dan $\sigma$ sebesar 0.8 dan 0.12 yang berdimensi kecil sehingga mudah dibawa. Hasil karakteristik return loss yang didapat cukup baik karena bernilai dibawah $-10 \mathrm{~dB}$. Sedangkan pola radiasi yang dihasilkan direksional pada setiap frekuensi. Namun hasil pola radiasi yang dihasilkan pada frekuensi 850 , 900, dan 2100 belum maksimal. Oleh karena itu desain antena ini cukup baik digunakan untuk pengukur radiasi BTS di frekuensi 1800 dan $2300 \mathrm{MHz}$.

\section{DAFTAR PUSTAKA}

[1] Hidayat and D. Ginting, "Rancang bangun perangkat pemantau shelter bts," J. Tek. Komput. Unikom - Komputika, vol. 2, no. 2, pp. 10-14, 2013.

[2] W. Ardiatna, A. N. Bakti, H. W. Nugroho, S. W. Hidayat, J. Sadrach, and S. Kadarwati, "Analisis Tingkat Emisi Radiasi Medan Elektromagnetik Dari BTS," J. Stand., vol. 15 , no. 2, pp. 144 152, 2013.

[3] G. A. Casula, P. Maxia, G. Montisci,G. Mazzarella, and F. Gaudiomonte, "A printed LPDA Fed by a coplanar waveguide for broadband applications,"
IEEE Antennas Wirel. Propag. Lett., vol. 12, no. August 2015, pp. 1232-1235, 2013.

[4] D. E. Anagnostou, J. Papapolymerou, M. M. Tentzeris, S. Member, and C. G. Christodoulou, "A Printed Log-Periodic Koch-Dipole Array ( LPKDA )," IEEE Antennas Wirel. Propag. Lett., vol. 7, 2008.

[5] M. A. Karim, M. Rahim, and H. Majid, "Log periodic fractal Koch antenna for UHF band applications," Prog. Electromagn. Res., vol. 100, pp. 201-218, 2010.

[6] G. A. Casula and P. Maxia, "A multiband printed log-periodic dipole array for wireless communications," Int. J. Antennas Propag., vol. 2014, 2014.

[7] C. A. Balanis, Antenna Theory Analysis and Design, 3rd ed. New Jersey: John Wiley \& Sons, Inc, 2005.

[8] R. Carrel, "The Design of log-periodic dipole antennas," Urbana, Illinois, 1961.

[9] M. Bloom, S. Fagan, J. Morin, N. G. Hallas, D. F. Pingree, and C. Michaud, The ARRL Antenna Book for Radio Communications, 22th ed. Newington: ARRL, 2011.

[10] H. Andre and U. Khayam, "Antena Kupu - Kupu Sebagai Sensor Ultra High Frequency ( UHF ) Untuk Mendeteksi Partial Discharge Pada Gas Insulation Substation," JNTE, vol. 2, no. 2, pp. 8-17, 2013.

[11] H. Andre, K. Kananda, A. R. Timor, Khairullah, Erliawati, and Z. Hendri, "Perancangan Modifikasi Antena KupuKupu Panjang Dual Frekuensi untuk Aplikasi Hypherthermia," JNTE, vol. 4, no. 2, pp. 207-214, 2015.

[12] www.worldtimezone.com, "GSM World Coverage Map- GSM Country List by frequency bands," 2016. [Online]. Available:http://www.worldtimezone.co m/gsm.html. [Accessed: 26-Sep-2016].

[13] R. Hadinegoro, Y. K. Ningsih, and I. Surjati, "Ultra-Wideband Notched Characteristic Fed by Coplanar Waveguide," Makara J. Technol., vol. 18, no. 3, p. 105, 2015. 


\section{Biodata Penulis}

Haryo Dwi Prananto, merupakan peneliti di Pusat Penelitian Sistem Mutu dan Teknologi Pengujian LIPI, saat ini aktif sebagai anggota kelompok penelitian Kompatibilitas
Elektromagnetik sejak tahun 2015.

Priyo Wibowo, merupakan peneliti bidang Kompatibilitas Elektromagnetik dan Aplikasi Pusat Penelitian Sistem Mutu dan Teknologi Pengujian,LIPI. 